\title{
The Soluble Isoform of CX3CL1 Is Necessary for Neuroprotection in a Mouse Model of Parkinson's Disease
}

\author{
Josh M. Morganti, ${ }^{1,2}$ Kevin R. Nash, ${ }^{1}$ Bethany A. Grimmig, ${ }^{2}$ Sonali Ranjit, ${ }^{3}$ Brent Small, ${ }^{4}$ Paula C. Bickford, ${ }^{2,5}$ \\ and Carmelina Gemma ${ }^{2,5}$ \\ ${ }^{1}$ Department of Molecular Pharmacology and Physiology, ${ }^{2}$ Department of Neurosurgery and Brain Repair, ${ }^{3}$ Morsani College of Medicine, and ${ }^{4}$ School of \\ Aging Studies, University of South Florida, Tampa, Florida 33612, and 5James A. Haley VA Hospital, Tampa, Florida 33620
}

The chemokine CX3CL1/fractalkine is expressed by neurons as a transmembrane-anchored protein that can be cleaved to yield a soluble isoform. However, the roles for these two types of endogenous CX3CL1 in neurodegenerative pathophysiology remain elusive. As such, it has been difficult to delineate the function of the two isoforms of CX3CL1, as both are natively present in the brain. In this study we examined each isoform's ability to regulate neuroinflammation in a mouse model of Parkinson's disease initiated by the neurotoxin 1-methyl-4-phenyl-1,2,3,6-tetrahydropyridine (MPTP). We were able to delineate the function of both CX3CL1 isoforms by using adenoassociated virus-mediated gene therapy to selectively express synthetic variants of CX3CL1 that remain either permanently soluble or membrane bound. In the present study we injected each CX3CL1 variant or a GFP-expressing vector directly into the substantia nigra of CX3CL1 $1^{-I-}$ mice. Our results show that only the soluble isoform of CX3CL1 is sufficient for neuroprotection after exposure to MPTP. Specifically, we show that the soluble CX3CL1 isoform reduces impairment of motor coordination, decreases dopaminergic neuron loss, and ameliorates microglial activation and proinflammatory cytokine release resulting from MPTP exposure. Furthermore, we show that the membrane-bound isoform provides no neuroprotective capability to MPTP-induced pathologies, exhibiting similar motor coordination impairment, dopaminergic neuron loss, and inflammatory phenotypes as MPTP-treated CX3CL1 ${ }^{-1-}$ mice, which received the GFP-expressing control vector. Our results reveal that the neuroprotective capacity of CX3CL1 resides solely upon the soluble isoform in an MPTP-induced model of Parkinson's disease.

\section{Introduction}

A key hallmark of Parkinson's disease (PD) is the dramatic depletion of dopaminergic (DA) neurons in the substantia nigra pars compacta (SNpc). While the exact etiology of the disease remains elusive, recent evidence suggests that microglial activation is a key component contributing to DA degeneration in the $\mathrm{SNpc}$ (Wu et al., 2002; Tieu et al., 2003; Cardona et al., 2006; Kim and Joh, 2006; Yasuda et al., 2008). Recent literature has identified the chemokine fractalkine (CX3CL1, FKN) as a neuroimmune regulatory protein signaling through its sole receptor (CX3CR1) exclusively on microglia with anti-inflammatory and thus neuroprotective effects (Harrison et al., 1998; Ransohoff et al.,

Received Jan. 30, 2012; revised Aug. 20, 2012; accepted Aug. 22, 2012.

Author contributions: J.M.M., P.C.B., and C.G. designed research; J.M.M., K.R.N., B.A.G., and S.R. performed research; J.M.M., K.R.N., B.S., P.C.B., and C.G. analyzed data; J.M.M., P.C.B., and C.G. wrote the paper.

This work was supported by U.S. Public Health Service Grant AG-04418 and the VA Medical Research Service (P.C.B.). We thank Dr. Adam D. Bachstetter for our discussions of CX3CL1 function and related neuron to glia communication pathways.

The authors declare no competing financial interests.

Correspondence should be addressed to Dr. Paula C. Bickford, Department of Neurosurgery and Brain Repair, University of South Florida, 12901 Bruce B. Downs Boulevard, MDC-78, Tampa, FL 33612. E-mail: pbickfor@health.usf.edu.

J.M. Morganti's present address: Brain and Spinal Injury Center, University of California San Francisco, San Francisco, CA 94110

C. Gemma's present address: Department of Anesthesiology and Pain Medicine, University of Washington, Seattle, WA 98195.

DOI:10.1523/JNEUROSCI.0539-12.2012

Copyright $\odot 2012$ the authors $\quad 0270-6474 / 12 / 3214592-10 \$ 15.00 / 0$
2007). Accordingly, multiple reports have begun to characterize CX3CL1-CX3CR1 interactions as important mechanisms of microglial regulation (Harrison et al., 1998; Zujovic et al., 2000, 2001; Mizutani et al., 2007; Wynne et al., 2010; Bachstetter et al., 2011; Pabon et al., 2011). Functionally, exogenous CX3CL1 peptide has been shown to inhibit microglial activation by downregulating the production of cytotoxic mediators (TNF $\alpha$, IL- $1 \beta$, iNOS, and IL-6) through multiple transduction pathways (Maciejewski-Lenoir et al., 1999; Garcia et al., 2000; Zujovic et al., 2000, 2001; Ré and Przedborski, 2006; Ransohoff et al., 2007). Endogenous expression of CX3CL1 produces a membraneanchored isoform that is proteolytically cleaved by ADAM10/17, yielding a soluble isoform. Both isoforms of CX3CL1 have been shown to ligate CX3CR1 (Chapman et al., 2000; Garton et al., 2001; Ré and Przedborski, 2006; Hundhausen et al., 2007; Ludwig and Weber, 2007). However, the individual signaling functions of each CX3CL1 isoform in a neurodegenerative condition are not fully understood.

In the present study, we investigated the neuroprotective capacity of each CX3CL1 isoform in a 1-methyl-4-phenyl-1,2,3,6tetrahydropyridine (MPTP) mouse model of PD. MPTP has been reliably used to induce DA cell loss in the SNpc of mice and non-human primates akin to what is observed in the human condition (Przedborski et al., 2001). To delineate the functional significance of each CX3CL1 isoform independently (soluble versus membrane bound), we constructed two recombinant adenoassociated viruses (rAAVs) that selectively expressed either 


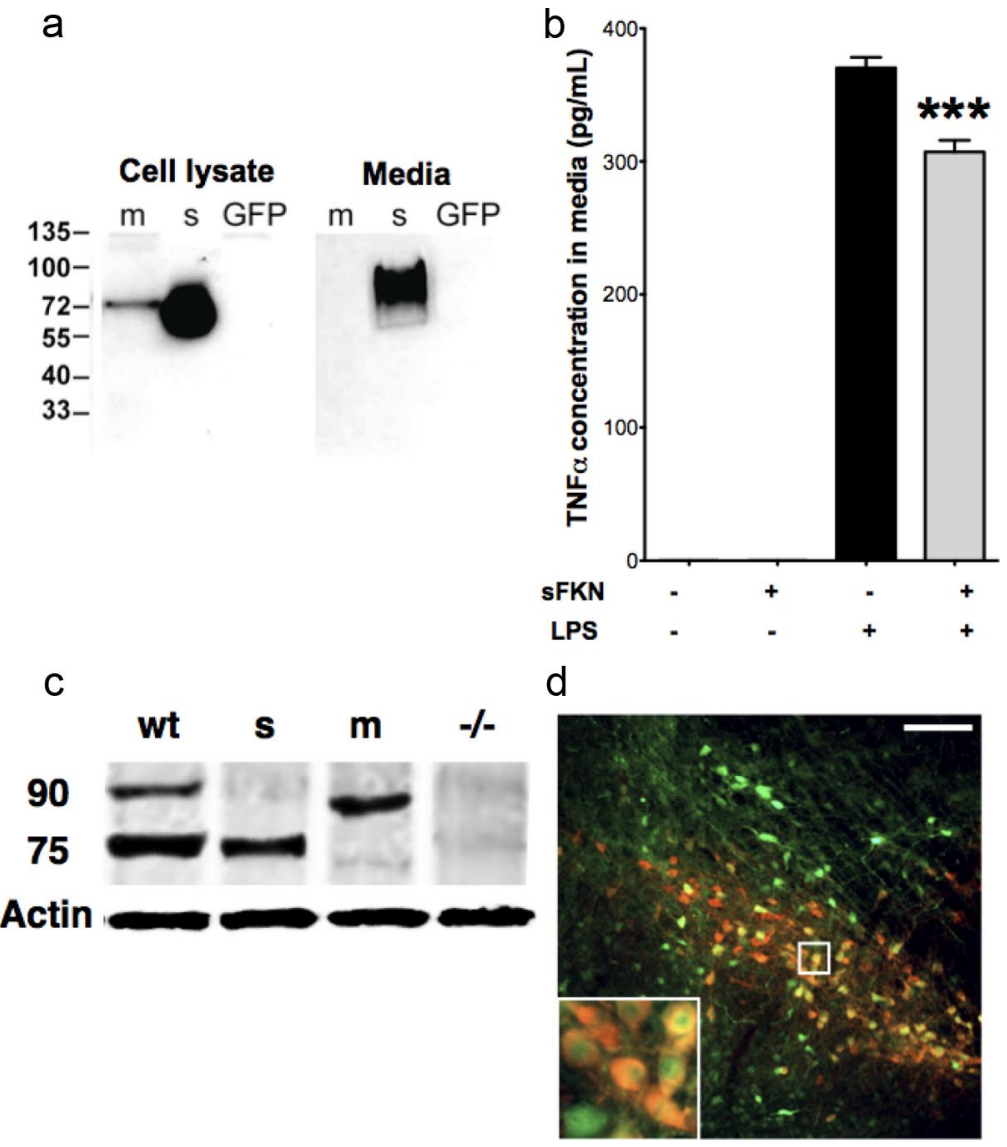

Figure 1. Generation and validation of rAAV-FKN variants. $\boldsymbol{a}$, Western blot analysis of $\mathrm{sFKN}(\mathrm{s}), \mathrm{mFKN}(\mathrm{m})$, and GFP expressed in HEK293 cells using an anti-hemagglutinin antibody. Only sFKN was detected in the medium, while both FKN variants were found in the crude cell lysate. $\boldsymbol{b}$, ELISA quantification of BV2 secreted TNF $\alpha$. Pretreatment with SFKN-conditioned medium attenuates $\left({ }^{* * *} p<0.05\right)$ the secretion of TNF $\alpha$ from BV2 cells when exposed to $100 \mathrm{ng}$ of LPS for $4 \mathrm{~h}$. Importantly, SFKN-conditioned media alone does not induce the secretion of TNF $\alpha$. c, Western blot analysis of in vivo expression of wild-type (wt), sFKN, mFKN, and $\mathrm{CX}_{3} \mathrm{CL}_{1}{ }^{-1-}(-/-)$ tissue lysates using an anti-CX3CL1 antibody. Both sFKN and mFKN produce a single band consistent in molecular weight with previous literature and relative to WT. Importantly, mFKN yields a single band, indicating that constitutive proteolytic cleavage by ADAM10/17 is abated. $\boldsymbol{d}$, In vivo expression pattern of rAAV-GFP, which uses the same promoter as the rAAV-FKN variants and CED vector delivery to the SNpc, resulted in transduction of numerous neurons of the SN. Green, GFP; red, $\mathrm{TH}^{+}$neurons; yellow-orange, colocalized expression. Scale bar, $200 \mu \mathrm{m}$. Data are presented as mean \pm SEM.

soluble CX3CL1 or a mutant isoform, which is proteolytically resistant to cleavage and remains membrane bound, as well as a control vector expressing green fluorescent protein (GFP). Each of the three vectors was injected into the SNpc of $\mathrm{CX} 3 \mathrm{CL1}^{-/-}$ mice such that the only CX3CL1 present was either solely soluble or membrane bound.

We therefore examined each isoform's ability to dampen the neurotoxic effects of MPTP, which were assessed through common behavioral, immunological, and biochemical assays. Our results show a significant reduction in the classic neurotoxic pathology associated with MPTP exposure in CX3CL1-null mice that received the vector expressing only the soluble isoform. Furthermore, CX3CL1-null mice, which expressed only the membranebound isoform of CX3CL1 in the SNpc, had pathologies akin to CX3CL1-null mice expressing the GFP control vector. These data suggest that the neuroprotective capacity of CX3CL1 is exclusively reliant on the soluble isoform in an MPTP model of PD.

\section{Materials and Methods}

AAV production. Recombinant AAV serotype 9 (rAAV9) vectors expressing the two different forms of CX3CL1 (GI:114431260) were cloned using PCR from mouse brain cDNA. The soluble form of fractalkine (sFKN; amino acids 1-336) was generated with primers Frac5' (GAGACCGGTCCA CCATGGCTCCCTCGCCGCTCGCG) and Frac3' (CTCGCTAGCTCACATGGCATAGTC AGGCACGTCATAAGGATAGCTAGAAGCC ATTGTGGCTGCCTGGGTGTCGGGGAC). The mutant membrane-bound form of fractalkine $(\mathrm{mFKN}$; mutations to stop ADAM10/17 cleavage into the soluble form, $\mathrm{R} 337 \mathrm{~A}+\mathrm{R} 338 \mathrm{~A}$ ) was generated by cloning two PCR fragments with primers Frac5' plus Fracma (GTAGCCCCACTGCCTGGGCAGCTGTGGC TGCCTGGGTG) and Frac3' (CTCGCTAGCT CACATGGCATAGTCAGGCACGTCATAAG GATAGCTAGAAGCCATCACTGGCACCAG GACGTATGAGTTAC) and Fracms (CACCCA GGCAGCCACAGCTGCCCAGGCAGTGGGG CTAC). sFKN and mFKN were cloned into the pTR2-MCS at the AgeI and NheI cloning sites. This vector contains the AAV2 terminal repeats and the hybrid cytomegalovirus-chicken $\beta$-actin promoter for CX3CL1 mRNA transcription. A hemagglutinin (HA) tag was added to the $\mathrm{C}$ terminus of both sFKN and mFKN with the PCR primers. rAAV9 vectors were generated and purified as described previously (Carty et al., 2010). rAAV particles are expressed as vector genomes $(\mathrm{vg}) / \mathrm{ml}$. Vector genomes were quantitated using a modified version of the dot plot protocol described by Zolotukhin et al. (2002). The protocol was modified to use a nonradioactive biotinylated probe for fractalkine generated by PCR. Bound biotinylated probe was detected with IRDye 800CW (Li-Cor Biosciences) and quantitated on the Li-Cor Odyssey. UF11 plasmid was used to generate rAAV9-expressing GFP as described previously (Carty et al., 2008).

In vitro cell culture experiments. sFKN conditioned medium was generated by transfection of HEK293 cells with Lipofectamine 2000 (Invitrogen) and the pTR2-sFKN plasmid. Cells were incubated in Opti-Mem (Invitrogen; containing $100 \mathrm{U} / \mathrm{ml}$ penicillin and 100 $\mu \mathrm{g} / \mathrm{ml}$ streptomycin) for $48 \mathrm{~h}$. Following incubation, medium was harvested and cleared by centrifugation at $2000 \times g$. The cleared sFKN conditioned medium was used for the proceeding cell culture experiment. BV2 cells (Blasi et al., 1990) were seeded at $5 \times 10^{5}$ cells per well in Opti-Mem (Invitrogen; supplemented containing $100 \mathrm{U} / \mathrm{ml}$ penicillin and $100 \mu \mathrm{g} / \mathrm{ml}$ streptomycin) of a 24 well plate and allowed to adhere for $16 \mathrm{~h}$. Immediately before treatment, cells were washed with fresh medium to remove any dead or nonadhered cells. Cells were treated with conditioned media, conditioned media plus LPS, LPS, or medium alone for $4 \mathrm{~h}$. Following incubation, medium was removed from each of the four groups and analyzed for TNF $\alpha$ using a commercial ELISA kit (R \& D Systems) following the manufacturer's protocol.

Animals. All experiments were conducted in accordance with the $\mathrm{Na}$ tional Institutes of Health Guide for the Care and Use of Laboratory Animals and were approved by the Institutional Animal Care and Use Committee of the University of South Florida College of Medicine (Tampa, FL). CX3CL1 $1^{-1-}$ mice (Merck Sharp \& Dohme) were backcrossed to the C57BL/6J (WT) background (The Jackson Laboratory) for $>10$ generations. Colonies of wild-type (WT) and CX3CL1 ${ }^{-1-}$ littermates were maintained at the University of South Florida, and genotyping was outsourced using a commercially available service (Transnetyx). Twelve- to sixteen-week-old WT and CX3CL1 $1^{-1-}$ littermates were used in the proceeding experiments. Mice were pair housed in environmen- 
tally controlled conditions $\left(12: 12 \mathrm{~h}\right.$ light:dark cycle at $\left.21 \pm 1^{\circ} \mathrm{C}\right)$ and provided food and water ad libitum.

Surgical procedure. Mice for the treatment groups were randomly selected and age stratified to ensure equal representation. Three groups of 12 - to 16 -week-old male $C X 3 C L 1^{-1-}$ mice $(n=30$ per group) were injected with $\mathrm{mFKN}, \mathrm{sFKN}$, or a vector expressing GFP for viral and protein control, while WT mice were injected with sterile saline $(n=60)$. Briefly, mice from each rAAV group received $1.5 \mu \mathrm{l}$ at $1 \times 10^{12} \mathrm{vg} / \mathrm{ml}$ $(2.5 \mu \mathrm{l} / \mathrm{min}$ ) bilateral direct injections into the SNpc (anteroposterior, -2.8 ; mediolateral, \pm 1.4 ; dorsoventral, -4.6$)$ using a convectionenhanced delivery (CED) 26 gauge needle (Carty et al., 2010). WT mice and an additional group of $C X 3 C L 1^{-1-}$ mice $(n=15)$ received sterile saline via the same injection parameters.

Acute MPTP administration. Six weeks following SNpc injections, sFKN-, mFKN-, and GFP-treated CX3CL1 ${ }^{-1-}$ mice were weighed and serially injected with MPTP. Additionally, the group of WT mice were weighed and randomly split such that half received either serial injections of MPTP (WT-MPTP) or sterile saline to serve as a double sham for both surgery and injection paradigms (WT-Sham). Lastly, the group of CX3CL1 ${ }^{-1-}$ mice that received intracranial saline also received i.p. saline as well ( $\mathrm{FKN}^{-/-}$Sham). This group served to examine whether there was a genotype effect in the baseline of all endpoints. MPTP injections were administered as previously described (Cardona et al., 2006). Briefly, MPTP (Sigma Aldrich; $10 \mathrm{mg}$ per kg body weight) was diluted in sterile saline and injected i.p. four times with a $1 \mathrm{~h}$ injection interval. Following injections, animal cages were placed on flexible, water-heating pads $\left(37^{\circ} \mathrm{C}\right)$ for $\sim 24 \mathrm{~h}$ postinjection in an effort to maintain body temperature and combat excessive mortality. After 5 days the mice were weighed, and mice that lost $>5 \%$ body mass were excluded from the study. Mortality ranged from $25-28 \%$ and was uniform across all groups of mice exposed to MPTP.

Behavioral analysis. Five days after MPTP injections, mice were tested for overall balance and motor coordination. This test was performed on an accelerating rotarod apparatus (Ugo Basile) with a $3 \mathrm{~cm}$ diameter rod starting at an initial rotation of $4 \mathrm{rpm}$ accelerating to $40 \mathrm{rpm}$ over $5 \mathrm{~min}$. Mice were tested for the time spent on the rod during each of four trials with a $30 \mathrm{~min}$ intertrial interval. Each trial was completed when the mouse fell off the rod (distance of $12 \mathrm{~cm}$ ) onto a spring-cushioned lever (Rogers et al., 2011). To assess motor coordination deficits and not motor learning, only the first three trials (day 1) were analyzed. Following behavioral analysis, animals were randomly divided for either perfusions or biochemical analyses.

Immunohistochemistry. Mice were euthanized with pentobarbital (50 mg/ kg, i.p.) and transcardially perfused with PBS, followed by $4 \%$ paraformaldehyde in PBS. The brains were postfixed in $4 \%$ paraformaldehyde for $12 \mathrm{~h}$, after which they were transferred into $30 \%$ sucrose in PBS for at least $16 \mathrm{~h}$ at $4^{\circ} \mathrm{C}$. Exhaustive coronal sections were made at $40 \mu \mathrm{m}$ using a Microm cryostat (Richard-Allan Scientific) and stored in cryoprotectant at $4^{\circ} \mathrm{C}$. Labeling of dopaminergic neurons was performed using an antibody against tyrosine hydroxylase (TH; 1:4000, Immunostar). Neurons were labeled using NeuN (Millipore, 1:500), which is a pan marker for neuronal nuclei. Activated microglia as well as T cells, were visualized with antibodies against CD68, $\mathrm{CD} 11 \mathrm{~b}$, and CD3 (Serotec 1:200). Standard staining procedures were conducted on free-floating sections using every sixth section for the entire SNpc and included sections before and after to ensure that the entire structure was sampled. Following incubations $(24-48 \mathrm{~h})$ with appropriate primary and biotinylated secondary antibodies, sections were treated with Vectastain $\mathrm{ABC}$ reagent (Vector Labs) and visualized with $\mathrm{DAB}$ reaction (Sigma). As a control measure, the specificity of all antibodies was confirmed by omitting primary antibodies.

Stereological quantification and imaging. To determine numbers for $\mathrm{TH}^{+}$and $\mathrm{CD}^{+}$cells, the optical fractionator method of unbiased stereological cell counting techniques (West et al., 1991) was used with a Nikon Eclipse 600 microscope and quantified using Stereo Investigator software (MicroBrightField). The virtual grid $(150 \times 150 \mu \mathrm{M})$ and counting frame $(75 \times 75 \mu \mathrm{M})$ were optimized to count at least 200 cells per animal with error coefficients $<0.07$. Outlines of the anatomical structures were done using $10 \times / 0.45$ objective, and cell quantification was conducted using $60 \times / 1.40$ objective.

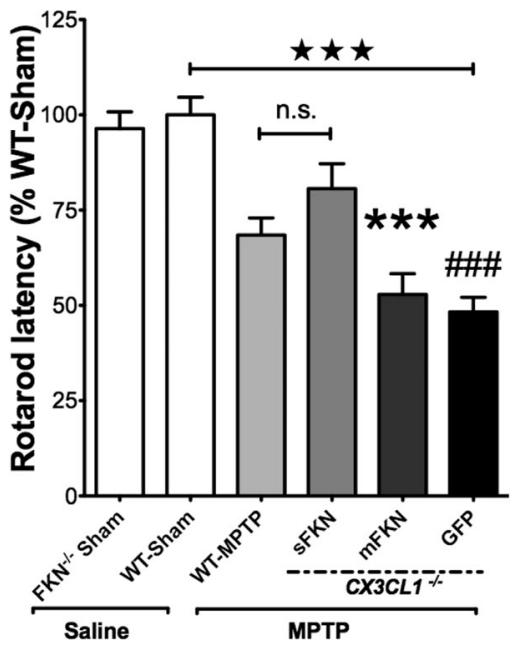

Figure 2. MPTP-induced impairment of motor coordination is rescued by sFKN. Five days after the last injections of MPTP or saline, mice were subjected to behavioral analysis to analyze balance and coordination on an accelerating rotarod. Motor coordination was assessed by the average of three trials during training. FKN ${ }^{-1-}$ sham group performed similarly to WT-Sham animals. As a whole, exposure to MPTP induced significant deficits in motor coordination compared to WT-Sham mice, which received sterile saline (three-way ANOVA; $F_{(1,145)}=42.11$, $\left.{ }^{\star \star \star} p<0.001\right) .\left(X 3 \mathrm{CL1}^{-1-}\right.$ mice that received sFKN performed significantly better than those which received mFKN (Tukey's HSD; ${ }^{* * *} p=0.002$ ) or GFP (Tukey's HSD; \#\#\# $<0.001$ ). Additionally, treatment with sFKN recovered the MPTP-induced motor coordination deficit akin to WT-Sham mice (Tukey's HSD; $p=0.380$ ). Data are presented as mean time in seconds as a percentage of WT-Sham \pm SEM. n.s. $=$ not significant.

Cell density quantification and imaging. Cell density was measured using a Zeiss Mirax slide scanner, as described previously (Rogers et al., 2011). Briefly, slides with NeuN-, CD68-, and CD11b-immunolabeled sections were scanned and converted into digital image files. Following scanning, the digital images were analyzed for positive area using Zeiss NeuroQuant IAE analysis software. An investigator unaware of sample treatment conditions defined the anatomical regions comprising the $\mathrm{SNpc}$ for each tissue section. Positive cells were defined using the analysis software based upon their threshold to include both the cell body and processes, while eliminating background values. Data are represented as the average area ratio of positive cells relative to the total measurement area.

Biochemical analysis tissue preparation. Mice used for biochemical studies were euthanatized by rapid decapitation. Brain tissues encompassing the ventral mesencephalon (VM) and striatum were separately dissected and rapidly frozen in liquid nitrogen before storage at $-80^{\circ} \mathrm{C}$. Tissues were homogenized using an electric tissue homogenizer in 1:10 weight-to-volume ratio of ice-cold RIPA buffer (Millipore) containing protease inhibitors and EDTA (Pierce). Following homogenization, sample lysates were centrifuged at $10,000 \times g$ at $4^{\circ} \mathrm{C}$ for $15 \mathrm{~min}$, and supernatant was collected. Protein concentration was determined using BCA assay (Pierce). Tissue lysates were used for subsequent Western blot and ELISA analyses.

Western blot analysis. Fifty micrograms of total protein per lane was loaded onto a $4-15 \%$ SDS-polyacrylamide gel (Bio-Rad) for electrophoresis. Proteins were transferred onto a nitrocellulose membrane for immunodetection. Membranes were subsequently blocked for $1 \mathrm{~h}$ in $5 \%$ nonfat dry milk (NFDM; Bio-Rad) in PBS-Tween (PBS-T; 0.1\% Tween 20). Anti-HA (1:500; Roche), anti-CX3CL1 (1:500, directed against $\mathrm{N}$ terminus; R \& D Systems), anti-CX3CR1 (1:800; Abcam), anti-TH (1: 500; Millipore), and mouse $\beta$-actin (1:3000; Sigma) were incubated overnight at $4^{\circ} \mathrm{C}$ in $1 \%$ NFDM in PBS-T. Following washes, appropriate secondary antibodies (Li-Cor) were incubated for $1 \mathrm{~h}$ at room temperature in $1 \%$ NFDM in PBS-T. Membranes were scanned using Li-Cor Odyssey near-infrared imager and raw intensity for each band was measured using Li-Cor Odyssey image analysis software. Scanned pseudocolor images were converted to black and white. 
a

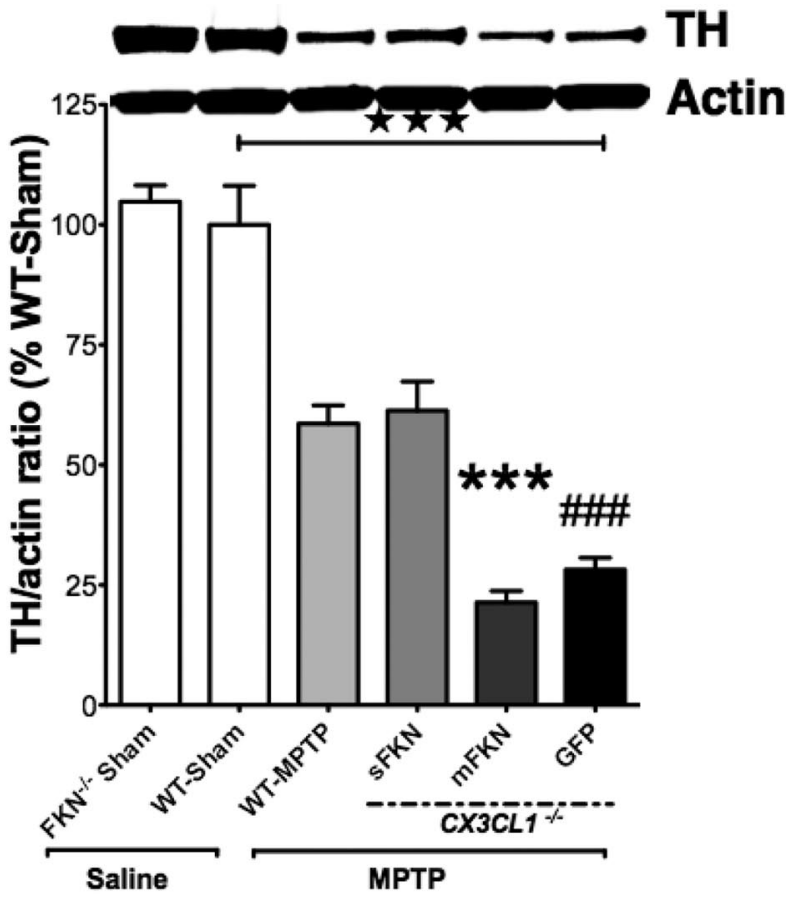

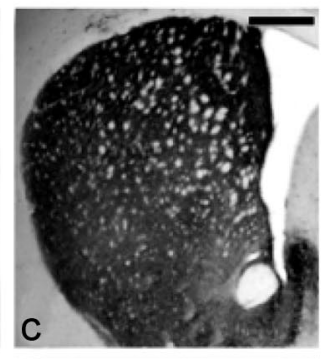

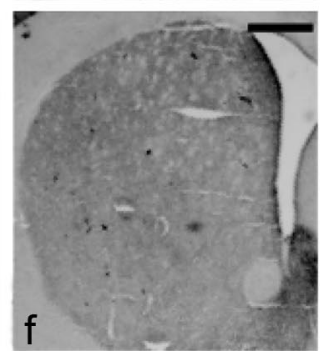

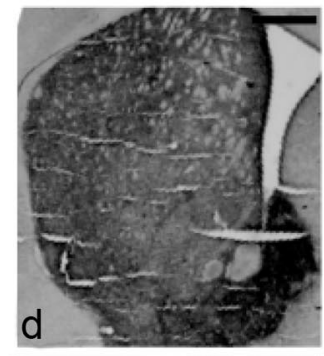

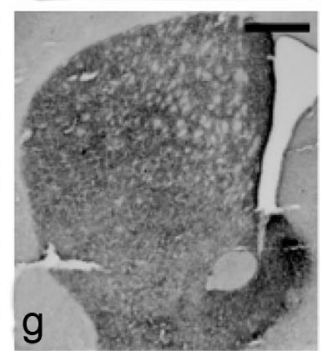

Figure 3. MPTP-depleted TH in the striatum is recovered by sFKN. Both hemispheres were rapidly dissected 7 days following the last MPTP or saline injections for biochemical analysis. $\boldsymbol{a}$, Western blot analysis revealed that MPTP exposure significantly reduced the availability of TH in the striatum (three-way ANOVA; $F_{(1,23)}=34.42,{ }^{\star \star \star} p<0.001$ ). Additionally, FKN ${ }^{-1-}$ sham animals had no distinguishable difference in TH production compared to WT-Sham mice. $\mathrm{XX} 3 \mathrm{CL}^{-1-}$ mice expressing sFKN in the SNpchad an attenuated loss of TH compared to mFKN (Tukey's HSD; ${ }^{* * *} p<0.001$ ) and GFP (Tukey's HSD; $\# \#$ \#\# $p .001$ ) expressing mice. There were no significant differences between $\mathrm{CX3CL1^{-1 }}$ mice expressing either mFKN or GFP (Tukey's HSD; $\left.p=0.627\right) . \boldsymbol{b}-\boldsymbol{g}$, Representative immunostaining in the striatum shows progressive loss of TH for FKN ${ }^{-1-}$ sham $(\boldsymbol{b})$, WT-Sham (c), WT-MPTP (d), $\operatorname{sFKN}(\boldsymbol{e}), \operatorname{mFKN}(\boldsymbol{f})$, and GFP $(\boldsymbol{g})$ groups. Data are presented as the mean band density ratio ( $n=5$ per group) of TH to actin as a percentage WT-Sham \pm SEM. Scale bars, $200 \mu \mathrm{m}$.

ELISA quantification. CX3CL1, TNF $\alpha$, and IL- $1 \beta$ concentrations were quantified using standard ELISA technique. VM lysates were run in triplicate at a concentration of $100 \mu \mathrm{g}$ per well and incubated overnight at $4^{\circ} \mathrm{C}$. Following incubation, the manufacturer's (RayBiotech) suggested protocol was followed. Optical density values for each ELISA plate were measured on a plate reader (BioTek), and sample concentrations were calculated based upon the supplied standard curve. Values were converted from $\mathrm{pg} / \mathrm{ml}$ to $\mathrm{pg} / \mu \mathrm{g}$ of protein loaded. Antibodies for CX3CL1 were directed against the $\mathrm{N}$ terminus.

Data analysis. All data were analyzed using SPSS software (IBM, version 20) and are presented as the mean \pm SEM. Statistical analyses were performed using three-way ANOVA accounting for genotype, MPTP, and rAAV treatments. Group differences were assessed by Tukey's honestly significant difference (HSD) post hoc multiple comparisons test, with $p$ values of $<0.05$ considered significant.

\section{Results \\ Generation and validation of rAAV9-FKN variants}

Both rAAV9-FKN variants produced a murine version of the CX3CL1 gene driven by the hybrid chicken $\beta$-actin cytomegalovirus promoter and were tagged with a HA peptide sequence for ease of detection. Before virus production, the rAAV vector was tested in HEK293 cells to evaluate the expression cassette. Cell lysate and conditioned media from transfected cells were examined using Western blot analysis to determine sFKN and mFKN expression. An anti-HA tag Western blot of transfected HEK 293 cells revealed that $\mathrm{sFKN}$ is readily secreted into the medium, while $\mathrm{mFKN}$ remains only in the cell lysate fraction (Fig. 1a). We next wanted to confirm that the synthetic FKN variants were biologically active. Briefly, conditioned medium from HEK 293 cells transfected with the sFKN plasmid was used to confer bioactivity by measuring the amount of secreted TNF $\alpha$ from BV2 microglia-like cells. It has been well documented that the induction of cytokine production from microglia as a result of LPS exposure can be blunted if the cells are pretreated with exogenous soluble CX3CL1 peptide (Zujovic et al., 2000; Mizuno et al., 2003; Lyons et al., 2009; Wynne et al., 2010). In accordance with previous literature, we show that BV2 cells preconditioned with sFKN-conditioned medium had an attenuated response to LPS (100 ng/ml) as measured by TNF $\alpha$ secretion (Fig. 1b). Furthermore, addition of sFKN-conditioned medium alone did not induce TNF $\alpha$ production. This attenuated response is comparable to previous literature (Mizuno et al., 2003; Lyons et al., 2009) given the dilute concentration of CX3CL1 found in sFKN-conditioned medium. As we were able to confer the functionality and bioactivity in vitro, we next examined the expression of the rAAV9FKN vectors in vivo. Using CX3CL1-null mice, we injected each vector bilaterally into the SNpc. Six weeks postinjection the harvested brain tissues were analyzed for sFKN and mFKN expression by Western blot. Using an anti-mouse CX3CL1 antibody, in vivo expressions of each of the rAAV-FKN constructs created their specific variants of CX3CL1 consistent with predicted molecular weights as we had previously documented (Bachstetter et al., 2011). Importantly, mFKN produces only a single band, indicating that the dibasic arginine mutation effectively inhibits 
cleavage by ADAM10/17 (Fig. 1c). Furthermore, direct injection using the CED method (Carty et al., 2010) with rAAV variants transduced numerous neurons throughout the $\mathrm{SNpc}$ (Fig. 1d). Viral transduction was not limited to DA neurons of the SNpc, as other nondopaminergic neurons were transduced. Of these populations, we found $>90 \%$ transduction of neurons (data not shown). Additionally, as we have documented previously (Carty et al., 2010), parenchymal injections of rAAV9 vectors via CED resulted in neuronal transduction with minimal astrocytic expression (data not shown).

\section{MPTP-induced impairment of motor coordination is ameliorated by $s F K N$ but not mFKN}

We next assessed the effects of each rAAVFKN treatment on MPTP-induced motor deficits using an accelerating rotarod. $\mathrm{FKN}^{-1-}$ Sham mice displayed no motor coordination impairment relative to WTSham (Fig. 2). Five days after the last MPTP injection, all MPTP-treated groups displayed a significant performance impairment $\left(F_{(1,145)}=42.11, p<0.001\right)$ as measured by average latency to fall across three trials compared to WTSham mice (Fig. 2). Treatment with sFKN significantly improved MPTP-induced behavioral deficits compared to $\mathrm{mFKN}$ $(p=0.002)$ and GFP $(p<0.001)$ viral control. Following rotarod performance assessment, mice were killed and striatal tissues were dissected for biochemical analysis. In agreement with each group's rotarod performance, Western blot analysis revealed significant loss of striatal TH as a result of MPTP administration $(p<$ 0.001 ), ranging from $40-75 \%$ (Fig. $3 a$ ). Furthermore, sFKN treatment was able to attenuate exhaustive striatal TH loss by 35 and $30 \%$ compared to $\mathrm{mFKN}(p<0.001)$ or GFP groups $(p<0.001)$, respectively.

\section{MPTP-induced neurodegeneration of SNpc is rescued by $s F K N$}

It has been previously documented that disruption of CX3CL1 signaling via genetic ablation of CX3CR1 in mice increases MPTP neurotoxicity in SNpc (Cardona et al., 2006). Seven days after the last MPTP injection, mice were transcardially perfused with a buffered paraformaldehyde solution and brain tissues were removed. We evaluated the level of MPTP-induced neurodegeneration in the SNpc through stereological quantification of $\mathrm{TH}$ (Fig. 4a) and by measuring the density of NeuN (Fig. 4b) staining. Additionally, $\mathrm{FKN}^{-1-}$ Sham mice showed no significant reduction in the number of $\mathrm{TH}$-positive neurons or the density of NeuN-stained neurons relative to WT-Sham, indicating that genetic disruption of CX3CL1 signaling alone does not produce a PD-like phenotype (Fig. 4a,b). Compared to WT- b
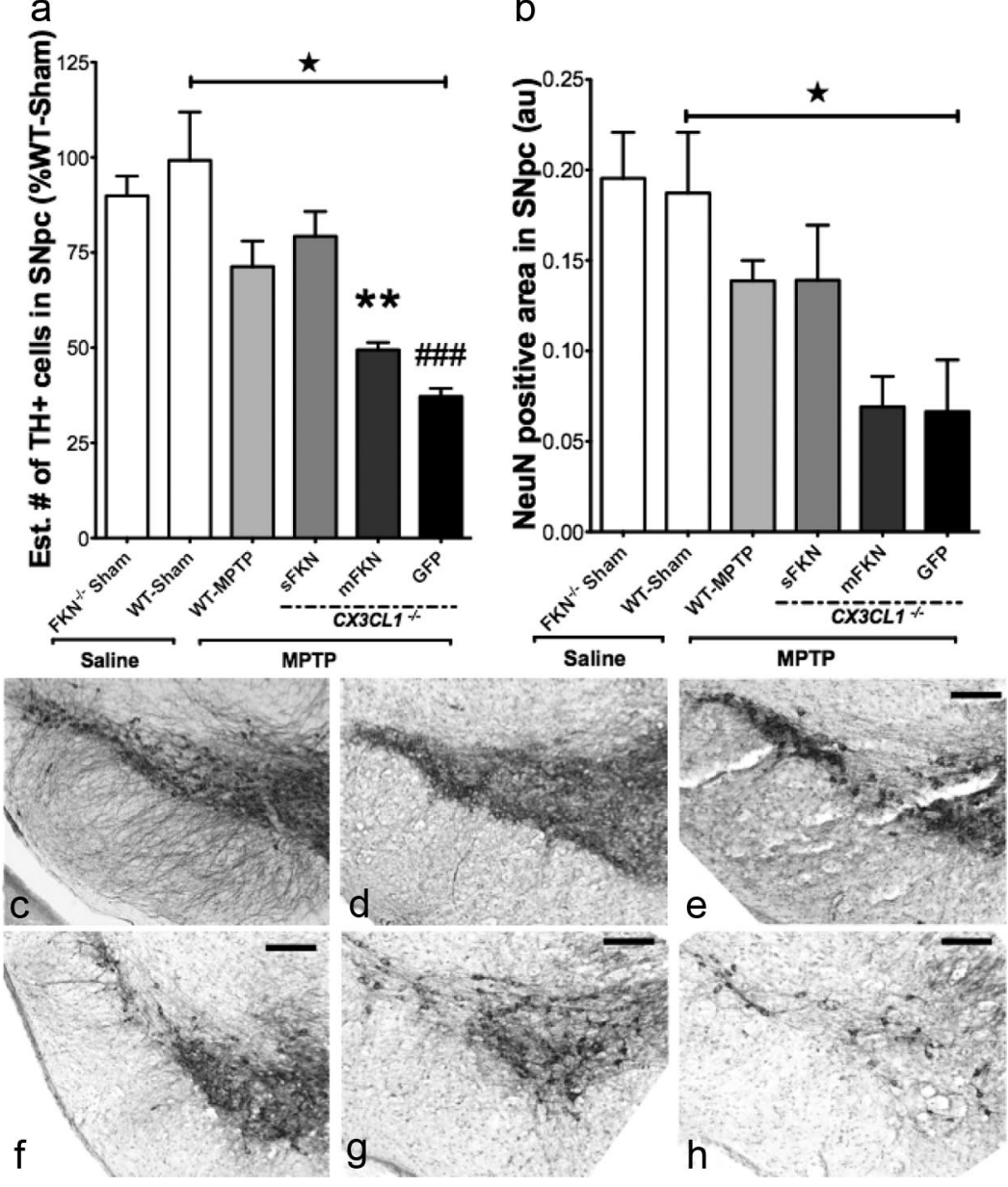

Figure 4. Stereological analysis of TH-positive neurons in the SNpc. TH immunoreactivity was analyzed in the SNpc of coronal sections made from mice 7 days after the final MPTP or saline injections. $\boldsymbol{a}$, Exposure to MPTP resulted in a marked reduction in the estimated number (Est. \#) of TH-positive cells in the SNpc (three-way ANOVA; $F_{(1,12)}=4.733,{ }^{\star} p=0.050$ ) compared to WTsham animals exhibited no phenotypic differences in $\mathrm{TH}^{+}$cell counts relative to WT-Sham mice. Further, SFKN provided the most significant TH neuroprotection relative to mFKN (Tukey's HSD; ** $p=0.003$ ) and GFP (Tukey's HSD; of NeuN ${ }^{+}$cells compared to WT-Sham (three-way ANOVA; $F_{(1,18)}=6.81,{ }^{\star} p=.018$ ), there were no significant differences revealed among group interactions (two-way ANOVA; $F_{(3,12)}=3.14, p=0.065$ ). Akin to $\mathrm{TH}^{+}$cell counts, there were no differences between FKN ${ }^{-1-}$ sham and WT-Sham animals for NeuN density. $\boldsymbol{c}-\boldsymbol{h}$, Representative immunostaining for TH in the SNpc for FKN ${ }^{-1-}$ sham $(\boldsymbol{c})$, WT-Sham- $(\boldsymbol{d})$, WT-MPTP- $(\boldsymbol{e})$, sFKN- $(\boldsymbol{f}), \mathrm{mFKN}-(\boldsymbol{g})$, and GFP-treated $(\boldsymbol{h})$ groups. Data are presented as mean estimate of $\mathrm{TH}^{+}$cells or mean density ratio as a percentage of WT-Sham \pm SEM. Scale bars, $200 \mu \mathrm{m}$.

Sham, MPTP exposure produced a marked reduction in the estimated number of TH-positive cells across all groups $\left(F_{(1,12)}=\right.$ 4.733, $p=0.050)$. As shown previously by Cardona et al. (2006), MPTP produced a larger lesion in the CX3CL1 ${ }^{-/-}$mice. sFKN treatment attenuated MPTP-induced dopaminergic cell loss compared to mFKN- $(p=0.003)$ and GFP-treated $(p<$ 0.001 ) animals. Furthermore, exposure to MPTP reduced the NeuN-positive cell density in the $\operatorname{SNpc}\left(F_{(1,12}\right)=4.733, p=$ $0.050)$, although there were no significant differences when groups were compared among each other $\left(F_{(1,12)}=3.14, p=\right.$ $0.065)$.

\section{Administration of MPTP does not alter CX3CL1-CX3CR1 signaling}

Recent literature has suggested that acute inflammatory insults can downregulate both transcript and protein levels of CX3CR1 on microglia (Kremlev and Palmer, 2005; Wynne et al., 2010). 

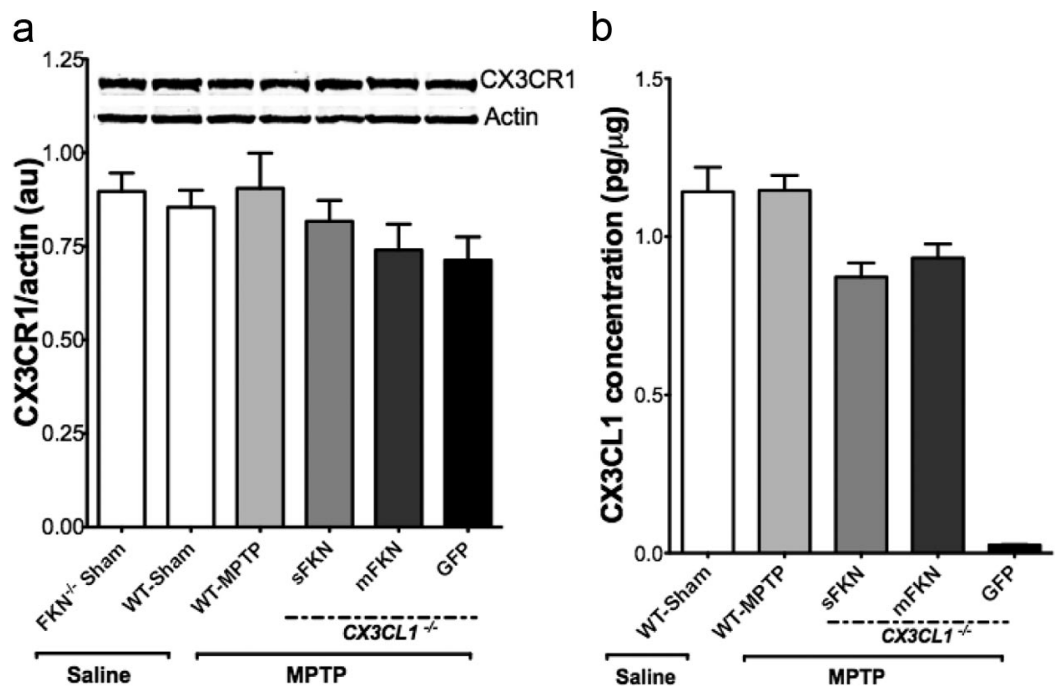

Figure 5. MPTP does not alter CX3CL1-CX3CR1 signaling in the VM. Tissue lysates from the VM of each group were analyzed for protein levels of either CX3CR1 by Western blot and CX3CL1 by ELISA. $\boldsymbol{a}$, Representative bands for CX3CR1 and actin for each group from Western blot analysis of VM tissue lysate using an anti-mouse CX3CR1 antibody. There were no significant alterations of CX3CR1 protein levels as a result of either MPTP or saline injections. Furthermore, neither the presence nor absence of CX3CL1 (regardless of isoform) affected protein levels of CX3CR1 (three-way ANOVA; $F_{(1,19)}=0.66, p=0.428$ ). $\boldsymbol{b}$, VM lysates were analyzed for CX3CL1 concentrations by standard ELISA. Exposure to MPTP did not alter the production of CX3CL1 compared to WT-Sham (three-way ANOVA; $F_{(1,23)}=3.74, p=0.066$ ). Furthermore, each rAAV-FKN variant sufficiently restored the levels of CX3CL1 in the VM to that resembling WT-Sham. Importantly, each variant expressed approximately the same amount of CX3CL1 (sFKN vs mFKN; Tukey's HSD; $p=0.703$ ). Data are presented as the mean band density ratio of CX3CR1 to actin and the mean concentration of CX3CL1 in pg/ $\mu \mathrm{g} \pm \mathrm{SEM}$. au, Arbitrary units.

We analyzed VM tissue lysate using Western blot analysis for CX3CR1 (Fig. 5a). Acute exposure to MPTP failed to affect $\left(F_{(1,19)}=\right.$ $0.66, p=0.428)$ the protein levels of CX3CR1 in vivo. Additionally, neither the presence of the individual rAAV-FKN variants nor the complete absence of CX3CL1 in the GFP group altered CX3CR1 protein levels in the $\operatorname{VM}\left(F_{(3,13)}=1.47, p=0.268\right)$. These data would suggest that expression of CX3CR1 is not only constitutive (Harrison et al., 1998) but also independent of the CX3CL1 isoform. Additionally, we quantified the production of CX3CL1 from each rAAV-FKN variant in the VM. Each rAAV-FKN variant was able to restore CX3CL1 levels resembling WTSham, and importantly sFKN and mFKN produced similar concentrations of CX3CL1 (Fig. 5b). Furthermore, here we show that MPTP does not affect the production of CX3CL1 (WT-Sham vs WT-MPTP; $p>0.05$ ).

\section{Induction of CD68- and CD11b-reactive microglia is attenuated by $s F K N$}

Microglial activation has been implicated in the propagation of SNpc neurotoxicity in multiple animal models of PD. Recent studies further report that an intact CX3CL1 to CX3CR1 signaling axis dampens the neurotoxic effects of both 6-OHDA and MPTP (Cardona et al., 2006; Pabon et al., 2011). Postmortem analysis of idiopathic PD patients has revealed strong immunoreactivity for CD68, a marker of phagocytic microglia (Croisier et al., 2005; Vroon et al., 2007). Furthermore, administration of MPTP has been reliably shown to induce this phagocytic microglial phenotype in the SNpc of mice (Vroon et al., 2007; Chung et al., 2010, 2011). Quantification of CD68-positive cell density revealed a significant induction of microglial reactivity (Fig. 6a) as a result of MPTP injections compared to WT-Sham $\left(F_{(1,26)}=4.25, p=\right.$ 0.046). Furthermore, loss of CX3CL1 ( $\mathrm{FKN}^{-1-}$ Sham) is not sufficient to induce significant upregulation of CD68 immunoreactivity. However, CD68 immunoreactivity was most profound in both the mFKN-treated $(p=0.001)$ and GFP-treated $(p<0.001)$ groups compared to sFKN. Furthermore, sFKNtreated mice resembled those of WT$\operatorname{MPTP}(p=0.971)$ in that there were very few CD68-positive cells. Here our data also show that mice treated with $\mathrm{mFKN}$ have a CD68 phenotype similar to that of mice with control AAV-GFP vector (Fig. $6 k, l ; p=0.913)$. We next analyzed a broader marker for microglial activation by using an antibody for CD11b. Immunolabeled CD11b microglia have previously been shown to increase reactivity following administration of the dopaminergic neurotoxin MPTP in the SNpc (Wu et al., 2003; Chung et al., 2011). Mice exposed to MPTP had a significant increase in CD11b-reactive microglia (Fig. $6 b)$ compared to WT-Sham $\left(F_{(1,27)}=\right.$ $7.35, p=0.021)$. Again, $\mathrm{FKN}^{-1-}$ Sham mice displayed no induction phenotype for this marker relative to WT-Sham mice. Moreover, mice that received sFKN injections again presented a similar CD11b expression phenotype as that of WT-MPTP ( $p=0.792)$. Furthermore, a strong induction of CD11b density by MPTP exposure was observed in the SNpc of both mFKN-treated (Fig. $6 m, p=0.007$ ) and GFP-treated (Fig. $6 n, p<0.001$ ) mice compared to sFKN-treated (Fig. 6j) CX3CL1-null mice. Additionally, CD11b immunoreactivity was similar following MPTP exposure between $\mathrm{mFKN}$ and GFPtreated CX3CL1-null mice $(p=0.499)$. Recent literature has identified a subset of cytotoxic $\left(\mathrm{CD} 4{ }^{+} \mathrm{CD} 28^{-}\right) \mathrm{T}$ cells that express CX3CR1, which is thought to mediate $\mathrm{T}$ cell entry to brain parenchyma in an animal model of multiple sclerosis (Broux et al., 2012). As others have shown (Brochard et al., 2009), we did observe an increase in $\mathrm{CD}^{+}$cells in the SNpc following MPTP exposure; however we did not find any differences between sFKN- and mFKN-treated mice (data not shown).

\section{Expression of MPTP induced proinflammatory cytokines is diminished by $\mathrm{sFKN}$}

Postmortem analysis of human PD tissue has shown that microglia are immunoreactive for multiple proinflammatory cytokines, including TNF $\alpha$ and IL-1 $\beta$ (McGeer and McGeer, 2004). Furthermore, mice that are genetically altered to inhibit cytokine production or are deficient in receptors for these cytokines provide neuroprotection in the SNpc following MPTP exposure (Klevenyi et al., 1999; Sriram et al., 2002). Accordingly, as CX3CL1 signaling has been shown to attenuate the production of these cytokines in vitro and in vivo following various inflammatory stimuli, we examined the anti-inflammatory properties of each rAAV-FKN variant in response to MPTP exposure in the CX3CL1-null mice. Tissue lysates of the VM were analyzed using standard ELISA techniques for the proinflammatory cytokines TNF $\alpha$ and IL-1 $\beta$. There was not a significant change in these cytokines for $\mathrm{FKN}^{-1-}$ Sham mice relative to WT-Sham mice. MPTP treatment significantly upregulated the production of TNF $\alpha$ (Fig. $\left.7 a ; F_{(1,23)}=18.36, p<0.001\right)$ and IL- $\beta$ (Fig. $7 b$; $\left.F_{(1,23)}=11.97, p=0.002\right)$ compared to all treatment groups. These findings are consistent with our data showing an in- 

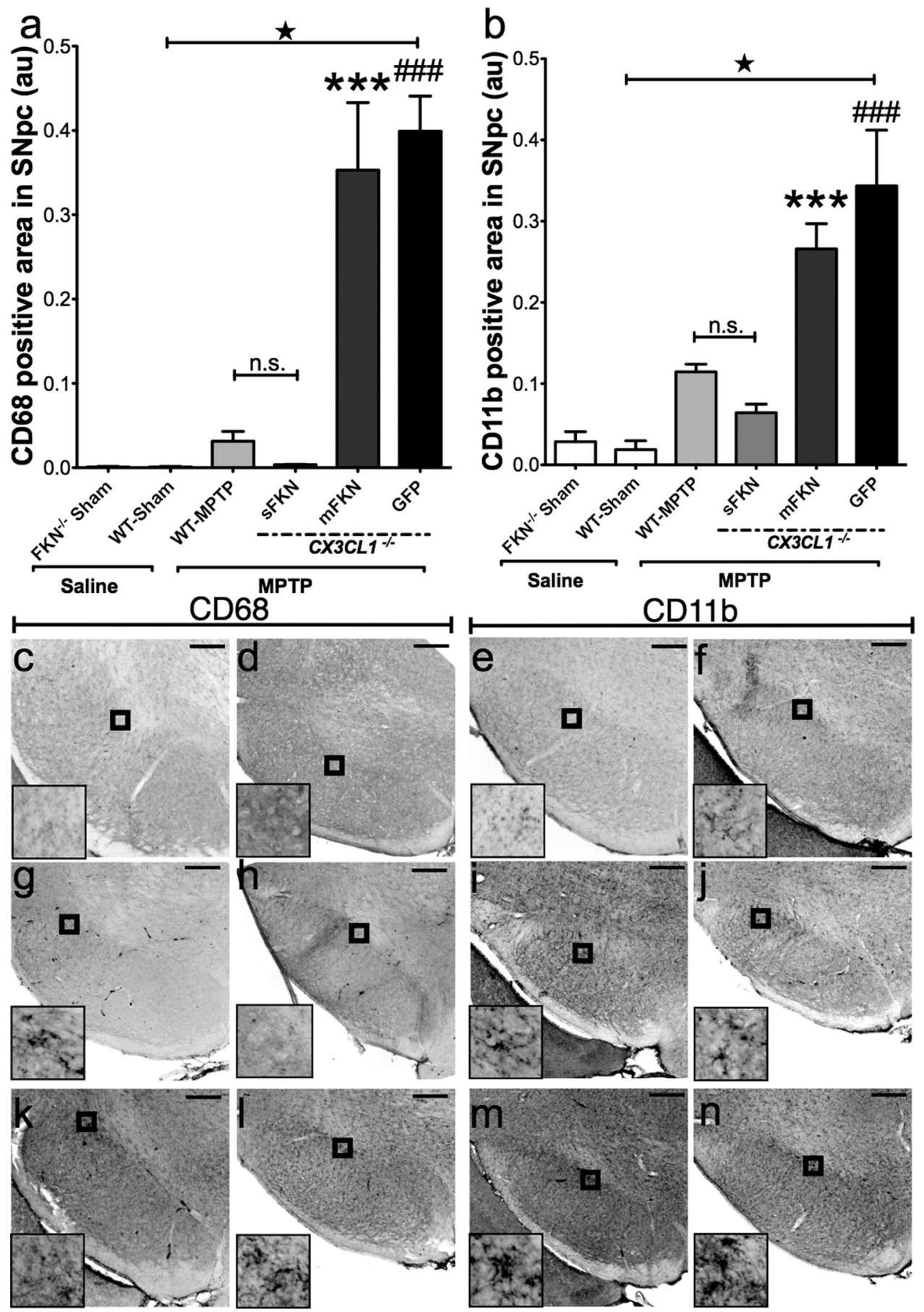

Figure 6. MPTP-induced activation of microglia in the SNpc is ameliorated by sFKN. Two markers of microglia activation in the SNpc were quantified using densitometric analysis. $\boldsymbol{a}$, MPTP exposure as a whole induced a significant immunoreactive profile for CD68 compared to saline injections (three-way ANOVA; $(F(1,26)=4.25, \star p=0.046)$. No difference was observed in CD68 staining for FKN ${ }^{-1-}$ sham mice compared to WT-Sham mice. Interestingly, CD68 immunoreactivity was noticeably absent in sFKN-treated mice, akin to levels found in WT-Sham. Furthermore, sFKN-expressing mice had a dramatic reduction in CD68 immunoreactivity relative to CX3CL1 ${ }^{-1-}$ mice expressing either mFKN (Tukey's HSD; ${ }^{* * *} p<0.001$ ) or GFP (Tukey's HSD; \#\#\# $p<0.001$ ). Although there was a visual induction of the CD68 phenotype in WT-MPTP mice, this was not significant compared to sFKN mice (Tukey's HSD; $p=$ 0.971). $\boldsymbol{b}$, Densitometric analysis of CD11b immunoreactivity in the SNpc. As a whole, MPTP exposure induced significant upregulation of CD11b immunoreactivity compared to saline injections (three-way ANOVA; $F_{(1,27)}=7.35,{ }^{\star} p=0.021$ ). There was a slight increase in CD11b reactivity for FKN ${ }^{-1-}$ sham mice, but this was not significant compared to the WT-Sham group. CX3CL1 ${ }^{-1-}$ mice expressing sFKN in the SNpc had a blunted response to MPTP compared to mFKN (Tukey's HSD; **** $p=0.007$ ) and GFP (Tukey's HSD; \#\#\# $p<0.001$ )-expressing mice. Similar to CD68 immunoreactivity, there were no significant differences between WT-MPTP and CX3CL1 ${ }^{-1-}$ mice expressing sFKN (Tukey's HSD; $\left.p=0.792\right)$. c-n, Representative immunoreactivity of CD68- and CD11b-reactive microglia in the SNpc for FKN ${ }^{-l-} \operatorname{sham}(\boldsymbol{c}, \boldsymbol{e})$, WT-Sham $(\boldsymbol{d}, \boldsymbol{f})$, WT-MPTP $(\boldsymbol{g}, \boldsymbol{i})$, sFKN $(\boldsymbol{h}, \boldsymbol{j}), \mathrm{mFKN}(\boldsymbol{k}, \boldsymbol{m})$, and GFP $(\boldsymbol{I}, \boldsymbol{n})$ groups, respectively. Inset images are high-power magnifications of their respective staining taken from the approximate location of the small black box. Data are presented as the mean area ratio \pm SEM. Scale bars, $200 \mu \mathrm{m}$. au, Arbitrary units; n.s., not significant. 

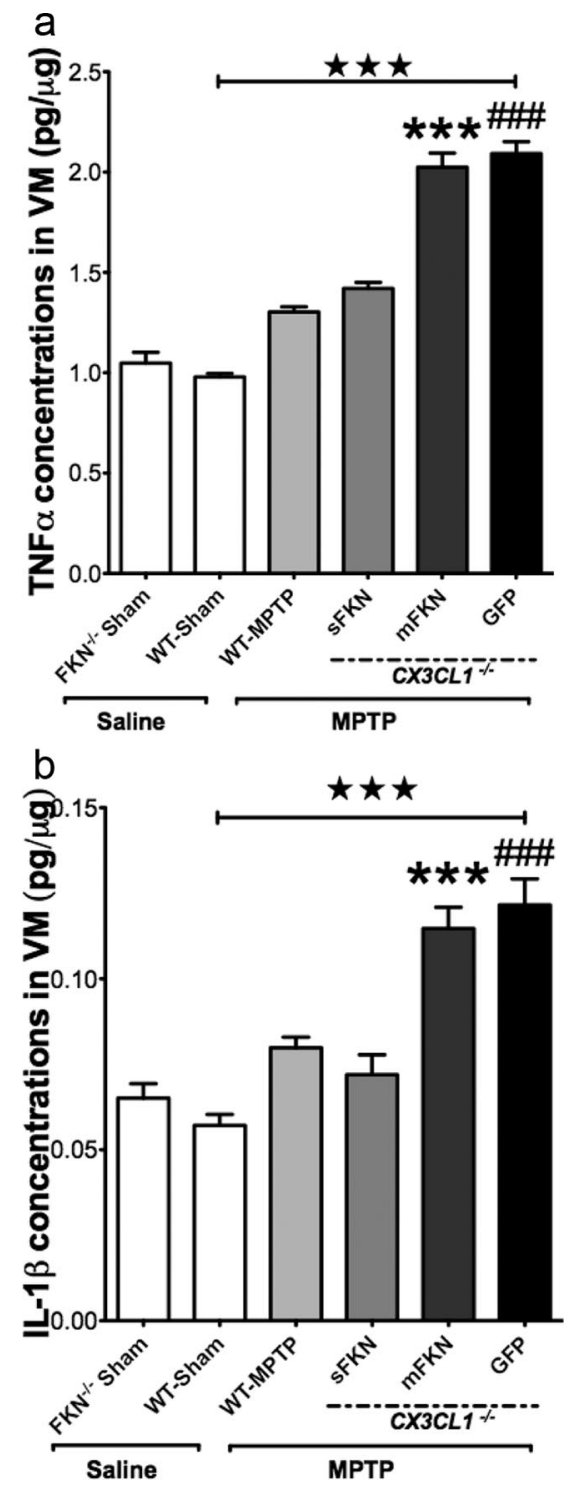

Figure 7. Induction of proinflammatory cytokines is attenuated in $\mathrm{CX}_{3} \mathrm{CL}^{-1-}$ mice expressing sFKN. TNF $\alpha$ and IL-1 $\beta$ concentrations were measured using standard ELISA techniques for VM lysates. $\boldsymbol{a}$, TNF $\alpha$ concentrations were upregulated following MPTP administration (three-way ANOVA; $F_{(1,23)}=18.36,{ }^{\star \star \star} p<0.001$ ). Comparatively, $\mathrm{CX3} \mathrm{CL}^{-1-}$ mice expressing sFKN in the SNpc had significantly lower concentrations of TNF $\alpha$ relative to mFKN (Tukey's HSD; ${ }^{* * *} p<0.001$ ) and GFP (Tukey's HSD; \#\#\# $p<0.001$ ) expressing mice. There were no significant differences between sFKN and WT-MPTP (Tukey's HSD; $p=$ 0.384 ) or mFKN and GFP (Tukey's HSD; $p=0.773$ ). $\boldsymbol{b}$, The IL- $1 \beta$ concentrations in the VM were significantly upregulated for mice exposed to MPTP (three-way ANOVA; $F_{(1,23)}=11.97$, $\left.{ }^{\star \star \star} p=0.002\right)$. Similar to the pattern of TNF $\alpha, I L-1 \beta$ concentrations in $C X 3 C L 1^{-1-}$ mice expressing sFKN were significantly blunted compared to both mFKN (Tukey's HSD; ${ }^{* * *} p=$ 0.001 ) and GFP (Tukey's HSD; ${ }^{\# \#} p<0.001$ ). As was observed with TNF $\alpha$, there were no significant differences in IL-1 $\beta$ concentrations between WT-MPTP and sFKN (Tukey's HSD; $p=$ 0.785 ) or mFKN and GFP (Tukey's HSD; $p=0.845$ ) expressing mice. Data are presented as the mean \pm SEM.

crease in activated microglia $\left(\mathrm{CD} 11 \mathrm{~b}^{+}\right.$and $\left.\mathrm{CD}_{68}{ }^{+}\right)$following exposure to MPTP. Interestingly, $s F K N$ attenuated the production of both TNF $\alpha(p<0.001)$ and IL-1 $\beta(p<0.001)$ compared to mFKN-treated and GFP-treated mice. Comparably, the production levels of both proinflammatory cytokines in sFKN mice were similar to the levels found in the WTMPTP group.

\section{Discussion}

Disruption of CX3CL1-CX3CR1 signaling in the brain increases MPTP-induced DA neurodegeneration (Cardona et al., 2006). Functionally, this signaling pair has been shown across a variety of studies to dampen microglial activation and subsequent toxicity. Until now, it has been difficult to isolate the individual effects of the two forms of CX3CL1. We have developed a novel method to examine the individual properties of the soluble versus the uncleaved membrane-anchored isoforms of CX3CL1 through the use of rAAV gene therapy in CX3CL1-null mice. Our study demonstrates that only sFKN attenuates the neurotoxic effects of MPTP on the nigrostriatal network and that the membraneanchored mFKN isoform had no effect in this model. Here, we show that treatment with $\mathrm{sFKN}$ reduces impairment of motor coordination, prevents DA neuron loss, and ameliorates microglial activation and proinflammatory cytokine release, all of which are commonly associated with the MPTP mouse model of PD.

These important discoveries provide novel insight into the role for CX3CL1 signaling in an acute inflammatory state. We have previously reported that an exogenous truncated peptide of CX3CL1 was able to reduce 6-OHDA-associated neurotoxicity in a rat model of PD (Pabon et al., 2011). However, this model still left unaccounted the actions of the full-length membrane-bound CX3CL1 isoform, as native CX3CL1 (both soluble and membrane bound) was still present in these animals. Additionally, Lyons et al. (2009) concluded that membrane-bound CX3CL1 possesses the same anti-inflammatory abilities as its soluble counterpart. However, Lyons et al. (2009) neglected to inhibit the constitutive cleavage mechanism of ADAM10/17 in their experimental paradigm. Here we have addressed this concern by mutating the known cleavage site of CX3CL1, thus preventing the soluble variant from being produced. Furthermore, by using CX3CL1-null mice, we were able to isolate the effects of each rAAV-FKN variant in response to MPTP.

In the present study we showed that the MPTP-induced motor deficit was significantly ameliorated by treatment with sFKN but not mFKN. Accordingly, mice expressing sFKN had significantly more $\mathrm{TH}$ immunoreactivity in the striatum compared to both mFKN-expressing and GFP-expressing mice. Furthermore, the depletion of $\mathrm{TH}$-positive cells in the $\mathrm{SNpc}$ in response to MPTP was ameliorated by treatment with sFKN but not mFKN. Expression of $\mathrm{TH}$ has been shown to be somewhat plastic in response to MPTP, and therefore a decline in TH is not necessarily an indicative marker of degenerating DA neurons (JacksonLewis et al., 1995). To accurately assess whether neuronal loss was occurring, we measured the amount of NeuN staining in the SNpc. Our data show that the neuronal loss associated with MPTP administration shows an inclination of recovery by administration of sFKN but not $\mathrm{mFKN}$.

CX3CL1-to-CX3CR1 communication is one way that neurons are thought to directly interact with microglia. Several studies have indicated that an acute inflammatory insult such as LPS exposure is sufficient to disrupt this dialog via downregulation of CX3CR1 transcript and protein levels. Here we show that exposure to acute administration of MPTP does not, under these circumstances, affect the signaling capabilities of this pair, as both CX3CR1 and CX3CL1 protein levels remain unchanged in response to MPTP exposure. Importantly, each of our rAAV-FKN variants restores CX3CL1 back to levels seen in WT mice.

The aberrant activation of microglia has been shown to increase the pathophysiology associated with PD. Moreover, in 
vitro, a truncated CX3CL1 peptide has been shown to reduce the production of multiple proinflammatory molecules (Zujovic et al., 2000, 2001; Biber et al., 2007; Mizutani et al., 2007). Our current data show that only sFKN attenuates the production of both IL-1 $\beta$ and TNF $\alpha$ in the VM of MPTP-injected mice and reduces microglial expression of CD68 and CD11b. These data suggest that treatment with $\mathrm{mFKN}$ was not efficacious in reducing the histological and molecular proinflammatory phenotype.

There has been a recent surge in the literature regarding the role for CX3CL1 signaling in both physiological and pathological conditions. We have recently shown that genetic disruption of CX3CL1 signaling is sufficient to impair cognitive function (Rogers et al., 2011), while others have demonstrated both neuroprotective (Bhaskar et al., 2010) and neurotoxic (Fuhrmann et al., 2010; Lee et al., 2010) effects of CX3CL1 signaling. Here we report a novel interaction wherein CX3CL1-mediated anti-inflammatory control of microglia is accomplished solely through the soluble isoform in a MPTP mouse model of PD. In this model, through the exclusive interactions of sFKN and CX3CR1, we demonstrate that amelioration of impaired motor coordination is mediated through a reduction in microglial activation and subsequent proinflammatory response. These effects are completely absent in mice expressing only $\mathrm{mFKN}$. A role of the membrane-bound form has been demonstrated in the periphery in mice that only express either the membrane-bound or soluble forms of CX3CL1 (Kim et al., 2011). In these mice the soluble form is shown to be important for intestinal macrophages to form transepithelial dendrites; however, only the membrane-bound form was able to rescue Ly6C ${ }^{\text {low }} \mathrm{CX} 3 \mathrm{CR} 1^{\text {high }}$ monocytes. As such, a role for different types of CX3CL1 may depend upon the site of action.

Given that only the soluble form of CX3CL1 provides an antiinflammatory and therefore neuroprotective function in this model of PD, we suggest that ligation with the soluble but not the membrane-bound isoform allows for CX3CR1 internalization. Recent literature has indicated that multiple chemokine receptors actively retreat through internalization to the cytoplasm following ligation to affect downstream signaling pathways (Neel et al., 2005; Borroni et al., 2010). Although ligation of mFKN with CX3CR1 is possible through the chemokine domain, its permanent attachment to the membrane may prevent subsequent internalization to the cytoplasm of microglia, thereby altering any downstream effectors. Therefore, only the soluble domain of CX3CL1 can be readily internalized with CX3CR1 ligation. Recent literature corroborates this hypothesis in that CX3CR1 actively removes soluble CX3CL1 from the surrounding milieu, as CX3CR $1^{-1-}$ mice have substantially more circulating CX3CL1 (Cardona et al., 2008). Moreover, this justifies the need for the constitutive and endogenous proteolytic cleavage by ADAM10/17 to yield soluble CX3CL1 in an effort to maintain a constant neuroprotective dialog between neurons and microglia.

We have created two very effective tools to examine the signaling characteristics of the two native isoforms of CX3CL1. Although we used an acute inflammatory model to examine these effects, it is worth noting that the relationships we detailed in this study may not apply to all inflammatory-related neurodegenerative conditions. Further examination of both of the CX3CL1 isoforms in various animal models of neuroinflammation and degenerative disease models is necessary to expand our understanding of this unique chemokine signaling pair.

\section{References}

Bachstetter AD, Morganti JM, Jernberg J, Schlunk A, Mitchell SH, Brewster KW, Hudson CE, Cole MJ, Harrison JK, Bickford PC, Gemma C (2011)
Fractalkine and $\mathrm{CX}_{3} \mathrm{CR} 1$ regulate hippocampal neurogenesis in adult and aged rats. Neurobiol Aging 32:2030-2044. CrossRef Medline

Bhaskar K, Konerth M, Kokiko-Cochran ON, Cardona A, Ransohoff RM, Lamb BT (2010) Regulation of tau pathology by the microglial fractalkine receptor. Neuron 68:19-31. CrossRef Medline

Biber K, Neumann H, Inoue K, Boddeke HWGM (2007) Neuronal 'On' and 'Off signals control microglia. Trends Neurosci 30:596-602. CrossRef Medline

Blasi E, Barluzzi R, Bocchini V, Mazzolla R, Bistoni F (1990) Immortalization of murine microglial cells by a v-raf/v-myc carrying retrovirus. J Neuroimmunol 27:229-237. CrossRef Medline

Borroni EM, Mantovani A, Locati M, Bonecchi R (2010) Chemokine receptors intracellular trafficking. Pharmacol Ther 127:1-8. CrossRef Medline

Brochard V, Combadière B, Prigent A, Laouar Y, Perrin A, Beray-Berthat V, Bonduelle O, Alvarez-Fischer D, Callebert J, Launay JM, Duyckaerts C, Flavell RA, Hirsch EC, Hunot S (2009) Infiltration of CD4 ${ }^{+}$lymphocytes into the brain contributes to neurodegeneration in a mouse model of Parkinson disease. J Clin Invest 119:182-192. Medline

Broux B, Pannemans K, Zhang X, Markovic-Plese S, Broekmans T, Eijnde BO, Van Wijmeersch B, Somers V, Geusens P, van der Pol S, van Horssen J, Stinissen P, Hellings N (2012) $\mathrm{CX}_{3} \mathrm{CR} 1$ drives cytotoxic $\mathrm{CD} 4{ }^{+} \mathrm{CD} 28^{-} \mathrm{T}$ cells into the brain of multiple sclerosis patients. J Autoimmun 38:10-19. CrossRef Medline

Cardona AE, Pioro EP, Sasse ME, Kostenko V, Cardona SM, Dijkstra IM, Huang D, Kidd G, Dombrowski S, Dutta R, Lee JC, Cook DN, Jung S, Lira SA, Littman DR, Ransohoff RM (2006) Control of microglial neurotoxicity by the fractalkine receptor. Nat Neurosci 9:917-924. CrossRef Medline

Cardona AE, Sasse ME, Liu L, Cardona SM, Mizutani M, Savarin C, Hu T, Ransohoff RM (2008) Scavenging roles of chemokine receptors: chemokine receptor deficiency is associated with increased levels of ligand in circulation and tissues. Blood 112:256-263. CrossRef Medline

Carty NC, Nash K, Lee D, Mercer M, Gottschall PE, Meyers C, Muzyczka N, Gordon MN, Morgan D (2008) Adeno-associated viral (AAV) serotype 5 vector-mediated gene delivery of endothelin-converting enzyme reduces $A \beta$ deposits in APP + PS1 transgenic mice. Mol Ther 16:1580-1586. CrossRef Medline

Carty N, Lee D, Dickey C, Ceballos-Diaz C, Jansen-West K, Golde TE, Gordon MN, Morgan D, Nash K (2010) Convection-enhanced delivery and systemic mannitol increase gene product distribution of AAV vectors 5, 8, and 9 and increase gene product in the adult mouse brain. J Neurosci Methods 194:144-153. CrossRef Medline

Chapman GA, Moores K, Harrison D, Campbell CA, Stewart BR, Strijbos PJ (2000) Fractalkine cleavage from neuronal membranes represents an acute event in the inflammatory response to excitotoxic brain damage. J Neurosci 20:RC87. Medline

Chung YC, Kim SR, Jin BK (2010) Paroxetine prevents loss of nigrostriatal dopaminergic neurons by inhibiting brain inflammation and oxidative stress in an experimental model of Parkinson's disease. J Immunol 185: 1230-1237. CrossRef Medline

Chung YC, Kim SR, Park JY, Chung ES, Park KW, Won SY, Bok E, Jin M, Park ES, Yoon SH, Ko HW, Kim YS, Jin BK (2011) Fluoxetine prevents MPTP-induced loss of dopaminergic neurons by inhibiting microglial activation. Neuropharmacology 60:963-974. CrossRef Medline

Croisier E, Moran LB, Dexter DT, Pearce RKB, Graeber MB (2005) Microglial inflammation in the parkinsonian substantia nigra: relationship to alpha-synuclein deposition. J Neuroinflammation 2:14. CrossRef Medline

Fuhrmann M, Bittner T, Jung CKE, Burgold S, Page RM, Mitteregger G, Haass C, LaFerla FM, Kretzschmar H, Herms J (2010) Microglial Cx3cr1 knockout prevents neuron loss in a mouse model of Alzheimer's disease. Nat Neurosci 13:411-413. CrossRef Medline

Garcia GE, Xia Y, Chen S, Wang Y, Ye RD, Harrison JK, Bacon KB, Zerwes HG, Feng L (2000) NF- $\kappa$ B-dependent fractalkine induction in rat aortic endothelial cells stimulated by IL- $1 \beta$, TNF- $\alpha$, and LPS. J Leukoc Biol 67:577-584. Medline

Garton KJ, Gough PJ, Blobel CP, Murphy G, Greaves DR, Dempsey PJ, Raines EW (2001) Tumor necrosis factor-alpha-converting enzyme (ADAM17) mediates the cleavage and shedding of fractalkine $\left(\mathrm{CX}_{3} \mathrm{CL} 1\right)$. J Biol Chem 276:37993-38001. CrossRef Medline

Harrison JK, Jiang Y, Chen S, Xia Y, Maciejewski D, McNamara RK, Streit WJ, Salafranca MN, Adhikari S, Thompson DA, Botti P, Bacon KB, Feng L 
(1998) Role for neuronally derived fractalkine in mediating interactions between neurons and $\mathrm{CX}_{3} \mathrm{CR} 1$-expressing microglia. Proc Natl Acad Sci U S A 95:10896-10901. CrossRef Medline

Hundhausen C, Schulte A, Schulz B, Andrzejewski MG, Schwarz N, von Hundelshausen P, Winter U, Paliga K, Reiss K, Saftig P, Weber C, Ludwig A (2007) Regulated shedding of transmembrane chemokines by the disintegrin and metalloproteinase 10 facilitates detachment of adherent leukocytes. J Immunol 178:8064-8072. Medline

Jackson-Lewis V, Jakowec M, Burke RE, Przedborski S (1995) Time course and morphology of dopaminergic neuronal death caused by the neurotoxin 1-methyl-4-phenyl-1,2,3,6-tetrahydropyridine. Neurodegeneration 4:257-269. CrossRef Medline

Kim KW, Vallon-Eberhard A, Zigmond E, Farache J, Shezen E, Shakhar G, Ludwig A, Lira SA, Jung S (2011) In vivo structure/function and expression analysis of the $\mathrm{CX}_{3} \mathrm{C}$ chemokine fractalkine. Blood 118:e156-e167. CrossRef Medline

Kim YS, Joh TH (2006) Microglia, major player in the brain inflammation: their roles in the pathogenesis of Parkinson's disease. Exp Mol Med 38: 333-347. Medline

Klevenyi P, Andreassen O, Ferrante RJ, Schleicher JR Jr, Friedlander RM, Beal MF (1999) Transgenic mice expressing a dominant negative mutant interleukin-1beta converting enzyme show resistance to MPTP neurotoxicity. Neuroreport 10:635-638. CrossRef Medline

Kremlev SG, Palmer C (2005) Interleukin-10 inhibits endotoxin-induced pro-inflammatory cytokines in microglial cell cultures. J Neuroimmunol 162:71-80. CrossRef Medline

Lee S, Varvel NH, Konerth ME, Xu G, Cardona AE, Ransohoff RM, Lamb BT (2010) CX3CR1 deficiency alters microglial activation and reduces betaamyloid deposition in two Alzheimer's disease mouse models. Am J Pathol 177:2549-2562. CrossRef Medline

Ludwig A, Weber C (2007) Transmembrane chemokines: versatile 'special agents' in vascular inflammation. Thromb Haemost 97:694-703. CrossRef Medline

Lyons A, Lynch AM, Downer EJ, Hanley R, O'Sullivan JB, Smith A, Lynch MA (2009) Fractalkine-induced activation of the phosphatidylinositol-3 kinase pathway attenuates microglial activation in vivo and in vitro. J Neurochem 110:1547-1556. CrossRef Medline

Maciejewski-Lenoir D, Chen S, Feng L, Maki R, Bacon KB (1999) Characterization of fractalkine in rat brain cells: migratory and activation signals for CX3CR-1-expressing microglia. J Immunol 163:1628-1635. Medline

McGeer PL, McGeer EG (2004) Inflammation and neurodegeneration in Parkinson's disease. Parkinsonism Relat Disord 10 [Suppl 1]:S3-S7.

Mizuno T, Kawanokuchi J, Numata K, Suzumura A (2003) Production and neuroprotective functions of fractalkine in the central nervous system. Brain Res 979:65-70. CrossRef Medline

Mizutani N, Sakurai T, Shibata T, Uchida K, Fujita J, Kawashima R, Kawamura YI, Toyama-Sorimachi N, Imai T, Dohi T (2007) Dose-dependent differential regulation of cytokine secretion from macrophages by fractalkine. J Immunol 179:7478-7487. Medline

Neel NF, Schutyser E, Sai J, Fan GH, Richmond A (2005) Chemokine receptor internalization and intracellular trafficking. Cytokine Growth Factor Rev 16:637-658. CrossRef Medline

Pabon MM, Bachstetter AD, Hudson CE, Gemma C, Bickford PC (2011) CX3CL1 reduces neurotoxicity and microglial activation in a rat model of Parkinson's disease. J Neuroinflammation 8:9. CrossRef Medline

Przedborski S, Jackson-Lewis V, Naini AB, Jakowec M, Petzinger G, Miller R,
Akram M (2001) The parkinsonian toxin 1-methyl-4-phenyl-1,2,3,6tetrahydropyridine (MPTP): a technical review of its utility and safety. J Neurochem 76:1265-1274. CrossRef Medline

Ransohoff RM, Liu L, Cardona AE (2007) Chemokines and chemokine receptors: multipurpose players in neuroinflammation. Int Rev Neurobiol 82:187-204. CrossRef Medline

Ré DB, Przedborski S (2006) Fractalkine: moving from chemotaxis to neuroprotection. Nat Neurosci 9:859-861. CrossRef Medline

Rogers JT, Morganti JM, Bachstetter AD, Hudson CE, Peters MM, Grimmig BA, Weeber EJ, Bickford PC, Gemma C (2011) CX3CR1 deficiency leads to impairment of hippocampal cognitive function and synaptic plasticity. J Neurosci 31:16241-16250. CrossRef Medline

Sriram K, Matheson JM, Benkovic SA, Miller DB, Luster MI, O'Callaghan JP (2002) Mice deficient in TNF receptors are protected against dopaminergic neurotoxicity: implications for Parkinson's disease. FASEB J 16:1474-1476. CrossRef Medline

Tieu K, Ischiropoulos H, Przedborski S (2003) Nitric oxide and reactive oxygen species in Parkinson's disease. IUBMB Life 55:329-335. CrossRef Medline

Vroon A, Drukarch B, Bol JGJM, Cras P, Brevé JJP, Allan SM, Relton JK, Hoogland PVJM, Van Dam AM (2007) Neuroinflammation in Parkinson's patients and MPTP-treated mice is not restricted to the nigrostriatal system: microgliosis and differential expression of interleukin-1 receptors in the olfactory bulb. Exp Gerontol 42:762-771. CrossRef Medline

West MJ, Slomianka L, Gundersen HJ (1991) Unbiased stereological estimation of the total number of neurons in the subdivisions of the rat hippocampus using the optical fractionator. Anat Rec 231:482-497. CrossRef Medline

Wu DC, Jackson-Lewis V, Vila M, Tieu K, Teismann P, Vadseth C, Choi DK, Ischiropoulos H, Przedborski S (2002) Blockade of microglial activation is neuroprotective in the 1-methyl-4-phenyl-1,2,3,6-tetrahydropyridine mouse model of Parkinson disease. J Neurosci 22:1763-1771. Medline

Wu DC, Teismann P, Tieu K, Vila M, Jackson-Lewis V, Ischiropoulos H, Przedborski S (2003) NADPH oxidase mediates oxidative stress in the 1-methyl-4-phenyl-1,2,3,6-tetrahydropyridine model of Parkinson's disease. Proc Natl Acad Sci U S A 100:6145-6150. CrossRef Medline

Wynne AM, Henry CJ, Huang Y, Cleland A, Godbout JP (2010) Protracted downregulation of CX3CR1 on microglia of aged mice after lipopolysaccharide challenge. Brain Behav Immun 24:1190-1201. CrossRef Medline

Yasuda Y, Shimoda T, Uno K, Tateishi N, Furuya S, Yagi K, Suzuki K, Fujita S (2008) The effects of MPTP on the activation of microglia/astrocytes and cytokine/chemokine levels in different mice strains. J Neuroimmunol 204:43-51. CrossRef Medline

Zolotukhin S, Potter M, Zolotukhin I, Sakai Y, Loiler S, Fraites TJ Jr, Chiodo VA, Phillipsberg T, Muzyczka N, Hauswirth WW, Flotte TR, Byrne BJ, Snyder RO (2002) Production and purification of serotype 1, 2, and 5 recombinant adeno-associated viral vectors. Methods 28:158-167. CrossRef Medline

Zujovic V, Benavides J, Vigé X, Carter C, Taupin V (2000) Fractalkine modulates TNF- $\alpha$ secretion and neurotoxicity induced by microglial activation. Glia 29:305-315. CrossRef Medline

Zujovic V, Schussler N, Jourdain D, Duverger D, Taupin V (2001) In vivo neutralization of endogenous brain fractalkine increases hippocampal TNF $\alpha$ and 8 -isoprostane production induced by intracerebroventricular injection of LPS. J Neuroimmunol 115:135-143. CrossRef Medline 